\title{
SESSILE SERRATED ADENOMA OF APPENDIX: IS FECOLITH A CAUSE? AMIT KUMAR ${ }^{\mathrm{a}}$, ASHISH BANSAL ${ }^{\mathrm{b} 1}$, MURAD AHMED $^{\mathrm{c}}$ AND MAHBOOB HASAN ${ }^{\mathrm{d}}$ \\ ${ }^{a b}$ Department of Pathology, Varun Arjun Medical College, Shahjahanpur, Uttar Pradesh, India

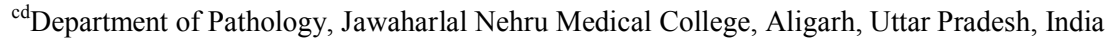

\begin{abstract}
Sessile serrated adenoma (SSA) originally conceptualized in 1990 shared his to pathological features of both hyper plastic polyps and adenoma. Traditionally sessile serrated adenomas were reported in colon, review of other similar lesions found that serrated adenomas may occur in appendix. The importance of recognizing these underreported proliferations is their link to colon carcinogenesis. The importance of extensive sampling and total processing of the appendectomy specimen, especially in patients greater than 30 years is of utmost importance in diagnosing sessile serrated adenomas. The present study was designed to study the association between acute appendicitis due to fecolith and sessile serrated adenomas. We entirely submitted 246 consecutive appendectomy specimens, with clinical diagnoses of acute appendicitis, at two institutions (Varun Arjun Medical College, (VAMC) and Jawahar Lal Nehru Medical College (JNMC), for a period of one year, from 2018-2019. Statistical analysis was done using Fischer 2 tailed exact test. Fecolith was seen in 142 cases of acute appendicitis and was more prevalent in JNMC $(47.9 \%, 46 / 96)$ as compared to VAMC $(43 \%, 65 / 150)$. The incidence of SSA in absence of fecolith was $5.8 \%$ when compared with presence of fecolith $(19.7 \%)$. This association was statistically significant $(\mathrm{P}=.002$, two-tailed). The study shows that SSA is strongly associated with fecolith related acute appendicitis, which may be a contributing factor in development of these proliferations. The role of meat rich, fiber lacking diet is a known factor for fecolith formation needs further evaluation in pathogenesis of SSA.
\end{abstract}

KEYWORDS: Sessile Serrated Adenoma, Fecolith, Acute Appendicitis

The concept of sessile serrated adenoma was introduced in 1990 after analysis of gastrointestinal polyps which shared histopathological features of both hyperplastic polyps and adenoma (Longacre and Fenoglio-Preiser, 1990). Traditionally sessile serrated adenomas were reported in colon and subsequently review of other similar lesions like mucosal hyperplasia of appendix, hyperplastic polyps and few mixed hyperplastic -adenomatous proliferations brought to light that serrated adenomas are underreported proliferations with incidence being as low as $1.7 \%$ (Torlakovic et al., 2003) (Lash and Genta, 2010) Recent studies applying WHO criteria (2010) and a revised modification increased the detection rate of these SSA's to $12.1 \%$ and $14.7 \%$, respectively. (Snover et al., 2010) (Bettington et al., 2014) Sampling of the entire appendix is advocated in cases of acute appendicitis for recognizing these small lesions. (Renshaw et al., 2006) Acute appendicitis is caused due to obstruction of the blind lumen due to foreign bodies, trauma, intestinal worms, lymphadenitis, and, most commonly, calcified fecal deposits known as appendicoliths or fecaliths. (Hollerman et al., 1988) We encountered three cases of SSA associated with acute appendicitis due to fecolith, during routine histopathological examination of appendectomy specimens. This prompted us to believe that fecolith obstruction may be a cause of SSA pathogenesis. To investigate this hypothesis we entirely submitted 246 consecutive appendectomy specimens, where acute appendicitis was a clinical diagnosis.

\section{MATERIALS AND METHODS}

We entirely submitted 246 consecutive appendix specimen for 1 years. (Janury to December 2018) at VAMC and JNMC with provisional clinical diagnoses of acute appendicitis. The numbers of cases were 150 at JNMC and 96 at VAMC. The presence or absence of fecolith was recorded in each specimen on gross examination and the maximum diameter of appendix was noted, subsequently Hematoxylin and Eosin stained sections were microscopically evaluated.

Sessile serrated adenomas were diagnosed using the criteria of distorted crypts showing surface serrations and dilated crypt bases with disorganized architecture with $\mathrm{L}$ or $\mathrm{T}$ shaped crypts, in conjunction with criteria of World Health Organization Classification of Tumours of the Digestive Tract (2010). (Snover et al., 2010) (Figure 1 \& 2). 


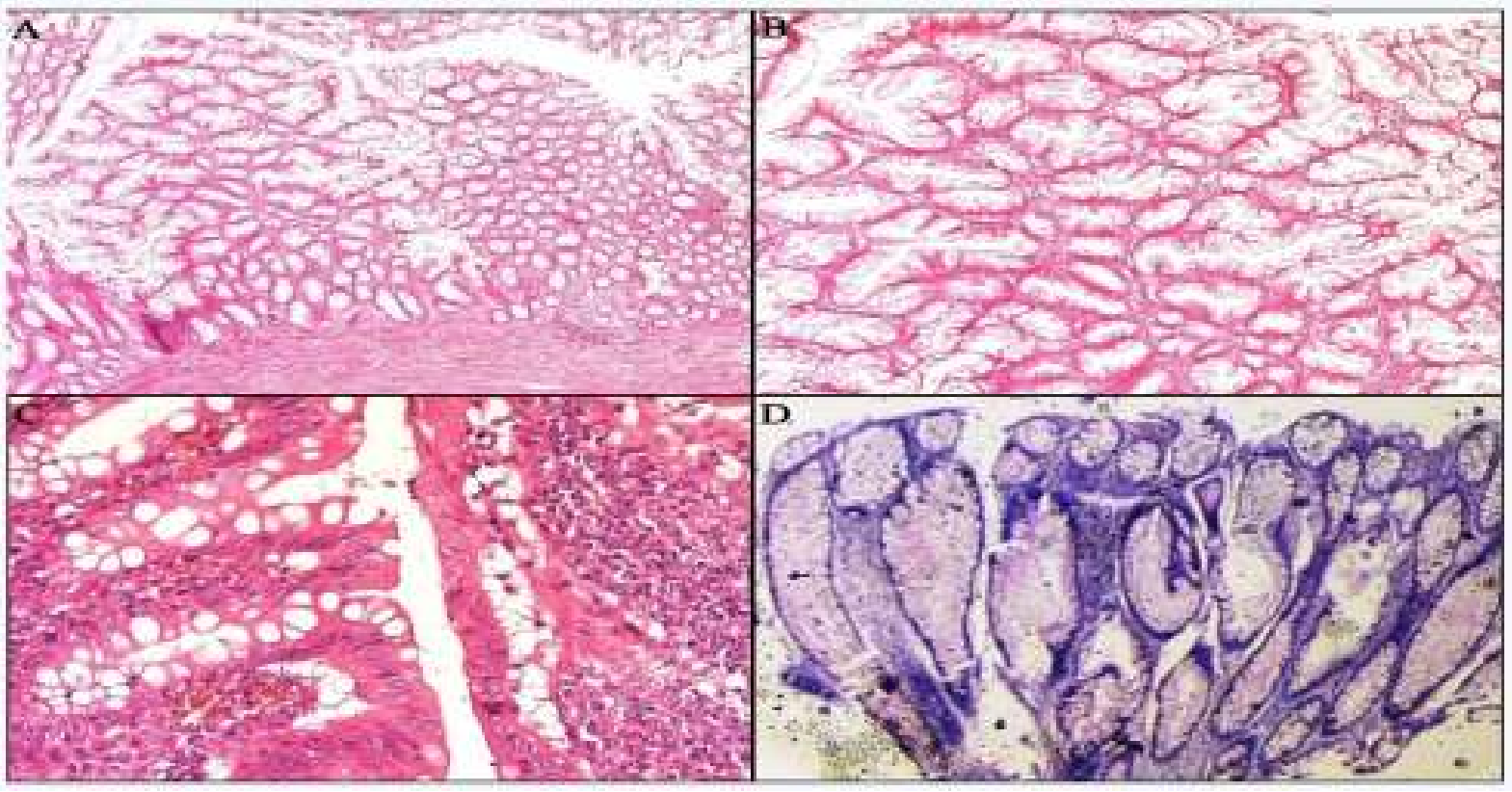

Figure 1: (A) Photomicrograph shows serrated gland with architectural distortion of the deep crypts, with $L$ and T shaped shaped arrangement of glands.(Hematoxlin and Eosin $x$ 20), (B): Photomicrograph shows the serrated glands lined by columnar cells with mucin depleted eosinophilic cytoplasm.(Hematoxlin and Eosin x 100), (C): Photomicrograph (original magnification, $x$ 400; H \& E stain) shows low-cytologic dysplasia, with inflammatory cells.(Hematoxlin and Eosin x 400)., (D): ): Photomicrograph (original magnification, x 100; H \& E stain) shows dilated glands and crypts with mild dysplasia.

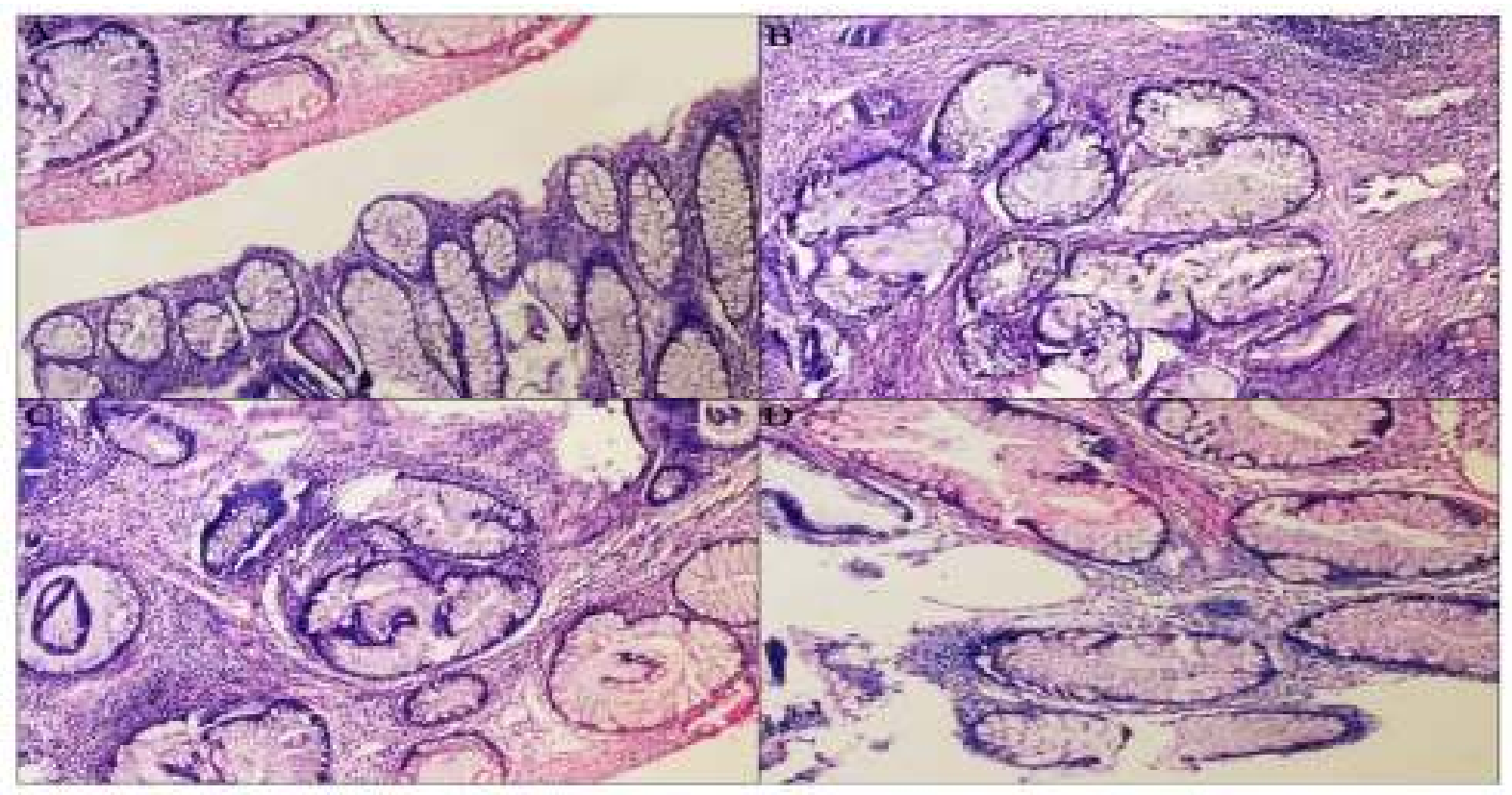

Figure 2: (A) Photomicrograph shows resemblance to hyperplastic polyp, with additional feature of pseudo stratification of glands and mild asymmetry. (Hematoxlin and Eosin $x$ 100), (B): Photomicrograph shows Low

grade dysplasia with stratified overlapping and distortion of glands. (Hematoxlin and Eosin $x$ 100), (C):

Photomicrograph shows Initiation of flattening and serrations in deep glands. (Hematoxlin and Eosin $x$ 100), (D):

Photomicrograph shows Serrated glands with mild dyspalsia. (Hematoxlin and Eosin $x$ 100) 
Statistical analysis was done using sigma plot v10.1.

\section{RESULTS}

Histopathological evaluation revealed 243 cases with features consistent with acute appendicitis. 3 cases showed normal histology, with no inflammation. Associated findings included 3 cases of carcinoid, 2 cases of enterobius infestation, 10 cases of lymphoid hyperplasia. (Table 1)

Fecolith was seen in 142 cases of acute appendicitis but was more prevalent in JNMC $(47.9 \%$, $46 / 96)$ as compared to VAMC $(43 \%, 65 / 150)$

SSA was identified in 34 cases of acute appendicitis. The incidence of SSA was relatively low when fecolith was absent (5.8\%) as compared to the presence of fecolith (19.7\%). On univariate analysis, presence of SSA showed significant association with fecolith associated appendicitis. The odds ratio (OR) and risk factor (RR) for this association were [OR 4.01(1.5910.08), RR 2.61(1.24-5.4) and this association was found to be significant by Fischer exact test $[(\mathrm{P}=.002$ (twotailed)]. (Table 2)

Table 1: Histopathological examination of 246 appendectomy specimens with clinical diagnoses of acute appendicitis

\begin{tabular}{|c|c|c|}
\hline & $\begin{array}{c}\text { Fecolith } \\
\text { present }\end{array}$ & $\begin{array}{c}\text { Fecolith } \\
\text { Absent }\end{array}$ \\
\hline Acute appendicitis & 142 & 104 \\
\hline Associated Findings & & \\
\hline Sessile serrated Adenoma & 28 & 06 \\
\hline Carcinoid & - & 03 \\
\hline Enterobius & - & 02 \\
\hline No inflammation & - & 03 \\
\hline Lymphoid hyperplasia & 06 & 04 \\
\hline
\end{tabular}

Table 2: Statistical analyses of SSA association with presence of fecolith

\begin{tabular}{|c|c|c|c|c|c|c|c|}
\hline & Total & $\begin{array}{c}\text { Fecolith } \\
\text { present }\end{array}$ & $\begin{array}{c}\text { Fecolith } \\
\text { Absent }\end{array}$ & $\begin{array}{l}\text { Fischer } \\
\text { Pvalue }\end{array}$ & $\begin{array}{l}\text { Odds } \\
\text { Ratio }\end{array}$ & $\begin{array}{c}\text { Risk } \\
\text { Ratio }\end{array}$ & $\begin{array}{c}\text { Chi-square test } \\
\text { Phi /Pvalue }\end{array}$ \\
\hline $\begin{array}{c}\text { SSA } \\
\text { absent }\end{array}$ & 212 & 114 & 98 & & & & \\
\hline $\begin{array}{c}\text { SSA } \\
\text { present }\end{array}$ & 34 & $\begin{array}{c}28 \\
\text { Incidence } \\
(28 / 142) * 100 \\
=19.7 \%\end{array}$ & $\begin{array}{c}06 \\
\text { Incidence } \\
(28 / 142) * 100 \\
=9.7 \%\end{array}$ & .002 & $\begin{array}{c}4.01(1.54 \\
-10.08)\end{array}$ & $\begin{array}{c}2.61(1.24- \\
5.49)\end{array}$ & $9.81 / .001$ \\
\hline
\end{tabular}

Another significant observation was that of the 28 fecolith associated SSA's, 21 were seen in the region where fecolith impaction caused maximum dilatation of the appendiceal lumen i.e. the cross section of fecolith was maximum and the appendiceal wall thickness minimum compared to rest of lumen. The lesions were

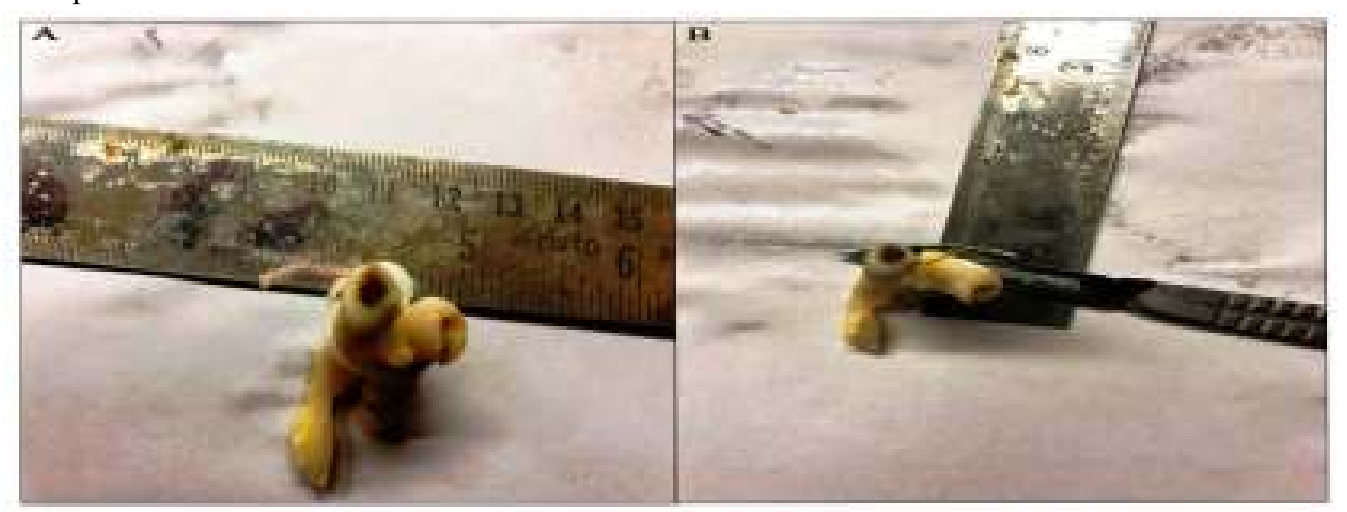

Figure 3: (A) Photograph showing cut appendix at maximum dilatation of lumen by fecolith, (B) Photograph showing section taken at area adjacent to mximum dilatation confined to a small sectional length, being less than $6 \mathrm{~mm}$ and were evident on only1 or 2 cross sections. (Figure 3)

An age wise distribution of cases (SSA) showed that all patients of were adults in age group of 32-50 years, with male to female ratio being 4.5:1 


\section{DISCUSSSION}

Acute appendicitis is the most common pathology of the appendix is often associated with fecolith. Fecolith formation is favoured by low fiber diet which in turn may be responsible for appendiceal obstruction leading to acute appendicitis (Jones et al., 1985). The incidence of fecolith in present study was more in the population of JNMC, where the majority of population had meat based principal diet, with lack of fiber.

The concept of SSA was introduced by Longario and Fenoglio-Preiser for a group of polyps showing cytological features of adenoma but with hyperplastic/serrated architechtural pattern. The exact histopathological features of SSA were described as branching crypts with dilatations at base and a growth pattern in which crypts seemed proliferating parallel to muscularis mucosae giving a $\mathrm{L} / \mathrm{T}$ shaped appearance (Snover et al., 2005). More recently, focal and diffuse appendiceal mucosal hyperplasia were defined as a rough equivalent of hyperplastic polyp and sessile serrated adenoma (Bellizzi et al., 2010). Torkovic et al. reviewed lesions like mucosal hyperplasia, inverted hyperplastic polyps and some mixed polyps and concluded that these lesions were morphologically more similar to SSA than hyperplastic polyps, making it apparent that SSA is more prevalent than thought and is under reported. (Torlakovic et al., 2003)

The incidence of SSA has been traditionally low, with Lash etal finding $1.7 \%$ of patients with mucosal polyps having SSA (Lash and Genta, 2010). However the detection rate for these lesions increased significantly, with the help of experienced pathologists. SSAs have been under-diagnosed by pathologists and often wrongly considered as hyperplastic polyps as illustrated by a recent study from Gill et al. in which three pathologists blinded to the original diagnosis re-examined the slides of all right sided polyps first labelled as hyperplastic polyps and re-classified $30-64 \%$ of them as SSAs (Gill et al., 2015). IJspeert et al. concluded that SSA/Ps are more common than previously reported, having an overall prevalence of $8.2 \%$, increasing to $9.0 \%$ for individuals older than 50 years, after analysing 4251 histologically confirmed polyps, in 3364 patients; 399 polyps were SSA (IJspeert et al., 2016). Similarly, in a retrospective study involving experienced pathologist by Abdeljawad et al., reported the total prevalence of $\mathrm{SSA} / \mathrm{Ps}$ as $8.1 \%$ (Abdeljawad et al., 2015). Bettington $M$ etal in their study involving 6340 colo-rectal polyps and strictly applying the diagnostic criteria outlined in the 2010 edition of the World Health Organization Classification of Tumours of the Digestive Tract, found that SSAs represented $12.1 \%$ of all polyps, further applying, a recent consensus publication proposing that polyps with as few as 1 SSA-type crypt should be diagnosed as an SSA, the prevalene of SSA's increased to $14.7 \%$, in their study and so they concluded that SSAs continue to be underdiagnosed in pathologic practice. (Snover et al., 2010) (Bettington et al., 2014) A colonoscopy based diagnostic study for SSA's involving 707 patients, of unselected series reported a high detection rate of $20.1 \%$. (Bettington et al., 2017)

The age of occurrence of SSA, in our study was found similar to previously published data. (Renshaw et al., 2006) (Rubio, 2004)

The routine guidelines for histologic processing of appendix recommend a longitudinal or cross section of the appendiceal tip and 2 additional cross sections ideally from middle portion and proximal margin. (Upton, 2010) The association of fecolith related acute appendicitis with SSA in our study raises the question that should all such specimens, be totally submitted? The serrated lesions tend to be quite small and a previous study suggested that these are no more than $6 \mathrm{~mm}$. in length. Our finding was similar, however, we noted that SSA was located in the area of maximal lumen dilatation due to the fecolith and where appendiceal wall thickness was minimum. Although ideally entire specimens should be submitted but due to practical difficulties in processing we suggest that in case of fecolith in appendix atleast 3 sections should be taken, one from the area with maximum dilatation and one each from the areas which are proximal and distal to it, apart from the routine sections. Since fecolith formation is much more common than SSA, we are of the opinion that it may be a contributing factor in development of SSA.

Rubeo has postulated serrated adenomas to be highly aggressive lesions and a polyp-adenoma carcinoma sequence, with reference to sessile serrated adenomas of the appendix. (Rubio, 2004) But in our study which had a comparatively large number of cases (34) as compared to their study (10 cases), we did not find any associated malignancy. The association of carcinogenesis with SSA has traditionally been reported in colon and studies have demonstrated SSA to be a precursor lesion with high microsatellite instability and loss of mismatch repair protein MLH-1. (Goldstein et al., 2003) But another study with reference to appendiceal 
serrated lesions, by Yantiss et al. did not find such associations. (Yantiss et al., 2007) So further studies are needed for establishing these adenomas at par with intestinal adenomas as a precursor lesion.

In this study we have demonstrated the association of fecolith with SSA and the indirect role of low fiber diet in development of these lesions, which occur in adults greater than 32 years of age. However the diagnosis requires extensive sampling so from a practical point of view we recommend that sections must be taken where fecolith causes maximum thinness of the appendiceal wall, where such lesions are most likely to occur, in addition to routine sections.

\section{REFERENCES}

Abdeljawad K., Vemulapalli K.C. and Kahi C.J., 2015. Sessile serrated polyp prevalence determined by a colonoscopist with a high lesion detection rate and an experienced pathologist. Gastrointest Endosc., 81(3): 517-24.

Bellizzi A.M., Rock J., Marsh W.L. and Frankel W.L., 2010. Serrated lesions of the appendix: a morphologic and immunohistochemical appraisal. Am. J. Clin. Pathol., 133(4): 623-32.

Bettington M., Walker N. and Rosty C., 2014. Critical appraisal of the diagnosis of the sessile serrated adenoma. American Journal of Surgical Pathology, 38: 158-166.

Bettington M., Walker N. and Rahman T., 2017. High prevalence of sessile serrated adenomas in contemporary outpatient colonoscopy practice. Intern. Med. J., 47(3): 318-323.

Gill P., Wang L.M. and Bailey A., 2013. Reporting trends of right-sided hyperplastic and sessile serrated polyps in a large teaching hospital over a 4-year period (2009-2012). Journal of Clinical Pathology, 66: 655-658.

Goldstein N.S., Bhanot P., Odish E. and Hunter S., 2003. Hyperplastic-like colon polyps that preceded microsatellite-unstable adenocarcinomas. Am. J. Clin. Pathol., 119(6): 778-96.

Hollerman J.J., Bernstein M.A., Kottamasu S.R. and Sirr S.A., 1988. Acute recurrent appendicitis with appendicolith. Am. J. Emerg. Med., 6(6): 614-7.

IJspeert J.E., de Wit K. and van der Vlugt M. 2016. Prevalence, distribution and risk of sessile serrated adenomas/polyps at a center with a high adenoma detection rate and experienced pathologists. Endoscopy, 48(8): 740-6.

Jones B.A., Demetriades D., Segal and Burkitt D.P., 1985. The prevalence of appendiceal fecaliths in patients with and without appendicitis. A comparative study from Canada and South Africa. Ann. Surg., 202(1): 80-82.

Lash R.H. and Genta R.M., 2010. Schuler Sessile serrated adenomas: prevalence of dysplasia and carcinoma in 2139 patients. J. Clin. Pathol., 63(8): 681-6.

Longacre T.A. and Fenoglio-Preiser C.M., 1990. Mixed hyperplastic adenomatous polyps/serrated adenomas. A distinct form of colorectal neoplasia. Am. J. Surg. Pathol., 14(6): 524-37.

Renshaw A.R., Kish R. and Gould E.W., 2006. Sessile Serrated Adenoma Is Associated With Acute Appendicitis in Patients 30 Years or Older. Am. J. Clin. Pathol., 126: 875-877.

Rubio C.A., 2004. Serrated adenomas of the appendix. J. Clin. Pathol., 57: 946-949.

Snover D.C., Ahnen D.J., Burt R.W. and Odze R.D., 2010. Serrated polyps of the colon and rectum and serrated polyposis. In: Bosman FT, Carneiro F, Hruban RH, et al, editors. WHO classification of tumours of the digestive system. Lyon, France: IARC, p. 160-5.

Snover D.C., Jass J.R., Fenoglio-Preiser C. and Batts K.P., 2005. Serrated polyps of the large intestine: a morphologic and molecular review of an evolving concept. Am. J. Clin. Pathol., 124: 380-391.

Torlakovic E., Skovlund E., Snover D.C., Torlakovic G. and Nesland J.M., 2003. Morphologic reappraisal of serrated colorectal polyps. Am. J. Surg. Pathol., 27: 65-81.

Upton M.P., 2010. Looking through a keyhole: serrated neoplasia in the vermiform appendix. Am. J. Clin. Pathol., 133(4): 529-32.

Yantiss R.K., Panczykowski A., Misdraji J., Hahn H.P., Odze R.D. and Rennert H., 2007. A comprehensive study of nondysplastic and dysplastic serrated polyps of the vermiform appendix. Am. J. Surg. Pathol., 31(11): 1742-53. 